\title{
The Impact of Creative Circles on EFL Learners' Reading Comprehension
}

\author{
Abdulaziz Ali Al-Qahtani \\ School of Education, Communication and Language Sciences, Newcastle University, Newcastle upon Tyne, NE1 7RU, \\ UK
}

Mei Lin

School of Education, Communication \& Language Sciences, King George VI Building, Newcastle University, Newcastle upon Tyne, NE1 7RU, UK

\begin{abstract}
The aim of this study was to investigate the impact of Creative Circles approach in developing Saudi EFL middle school learners' reading comprehension. The study was carried out at a Saudi middle school in Jeddah, involving three intact third grade classes. A triangulated approach was adopted in order to collect data by means of multiple instruments- reading comprehension test, reflective journals and semi-structured interviews over the period of a school term. The results revealed a significant improvement in the experimental group's reading comprehension abilities. The success of Creative Circles approach could be attributed to its adoption of collaborative reading as a teaching/learning technique, explicit teaching of reading skills, attention to low-level and high level reading processes and metacognitive awareness. Moreover, the experimental group as well as their teacher indicated that the new approach has immensely helped in addressing the issue of vocabulary learning. They also described the approach as efficient and flexible in large and mix-abilities classes.
\end{abstract}

Index Terms - creative circles, EFL, reading comprehension

\section{INTRODUCTION}

As one of the key language skills, reading can be perceived as a complex mental activity which integrates two processes: decoding a particular text (word recognition) and comprehension (grasping the meaning) behind the text (Gough, Hoover, \& Peterson, 1996). Based on this definition, the two processes interact with one another to establish understanding. To accomplish this result, word recognition must engage the learner's relevant schemata and initiate thinking about the collective meaning of a text (Collins \& Collins, 2002).

Reading is an indispensable skill for foreign language learners. In fact, Nuttall (1996, p.30) states that "language improvement is a natural by-product of reading." It is even considered as "an essential skill, perhaps the most important skill, taught in schools"(Collins \& Collins, 2002, p.9). In a foreign language classroom, learners are constantly constructing meaning of the texts before them regardless of the focus skill; and they need to comprehend, interpret, infer and draw conclusions. Alfassi (2004) emphasizes the point that as the learner matures, texts become a major source of information. Hence learning about and from reading is crucial. Therefore, a skilled reader can achieve greater levels of language proficiency than those who cannot read well.

Regrettably, reading is often marginalized in a Saudi EFL classroom settings. AL-Nifayee (2010) criticizes the reading activities inside these classes as being solely focused on grammar and vocabulary while ignoring other comprehension activities and strategies. Al-Mansour and Al-Shorman (2011, p.69), after discussing the importance of reading comprehension skills, state that: "most EFL students, especially school students, are often unable to comprehend a written text effectively". Furthermore, Al-Nujaidi (2003) points out that Saudi first year university students' reading ability is far below the acceptable standards and that their vocabulary is very limited (between 500 and 700 word families). Moreover, according to "Test and Score Data Summary" for the Educational Testing Services (2009, 2010, 2011, 2012), the TOEFL test scores of Saudi students were the lowest compared to their peers in other Middle Eastern countries in all four skills: listening, speaking, writing and especially reading, in which they even scored the lowest worldwide along with applicants from countries such as Guinea and Angola. Saudi students, along with students from the United Arab Emirates, also scored the lowest in the IELTS in 2012 in its two versions: Academic and General Training.

The aforementioned views are in agreement with the researcher's own observations during his fieldwork experience as an EFL teacher and supervisor for 16 years. Based on the researcher's classroom observations, teaching practices of the actual reading class involve: oversimplification of reading texts and activities, excessive use of L1, discouragement of interaction between students, under-emphasis of higher order thinking skills, lack of reading strategies training and feedback. Moreover, when testing reading, EFL teachers often provide students with passages and comprehension questions that were previously taught; and most of test items do not go beyond the literal level of comprehension. 
In the context of what was previously discussed about the current displeasing situation of teaching reading to Saudi EFL learners, it has become evident that there is a need to adopt a teaching strategy which improves reading comprehension of Saudi EFL learners. The answer, this research has proposed, might lie in Creative Circles approach. This study has been undertaken using a mixed methods methodology in order to advance the understanding of the impact of Creative Circles approach in developing Saudi EFL middle school learners' reading comprehension. The specific research objectives were to:

1. Determine the impact of Creative Circles approach on learners' reading comprehension

2. Gain students' perceptions on Creative Circles approach

\section{THEORETICAL FRAMEWORK}

\section{CREATIVE CIRCLES}

Creative Circles is a collaborative instructional model that is informed by Learning Circles strategy, which was introduced by Robert Karplus and Myron Atkin when they joined forces to build up a science teaching strategy intended to teach elementary level learners, coming in two steps of invention and discovery (Atkin \& Karplus, 1962). In 1967, an exploration phase was introduced to precede invention and discovery phases (Karplus \& Thier, 1967). In order to additionally explain the meaning of each phase for teachers, Karplus had to change the names of the phases into exploration, introduction, and application. Later variations were the $5 \mathrm{E}$ and the $7 \mathrm{E}$.

As shown in Figure 1 below, the phases of Creative Circles model begin with the engagement, whereby the teacher creates student interest, elicits students' questions, and ascertains students' prior knowledge with respect to the topic(s) to be read. During the exploration stage, the teacher encourages students to collaborate actively on reading tasks with other students with limited teacher input. The teacher provides directions and responds to students' questions while acting as a facilitator, providing students opportunities to seek their own answers to the problems. Within the explanation phase, which recurs at different time during the lesson, the teacher encourages students to explain concepts through teacher questioning while prompting students to give evidence to support their ideas. Also, in this phase, the teacher introduces formal definitions and explanations of ideas and information drawing upon students' experiences during the exploration activities. In the elaboration phase, the teacher encourages students to apply or extend their newly constructed concepts into different or real-life contexts. Assessment is ongoing throughout the lesson, whereby the teacher formatively observes and assesses students' learning as well as letting students assess their own learning. In the evaluation phase, a summative evaluation is developed. It takes the form of reflective journals, which students write to evaluate their own learning and identify strengths and areas of improvement.

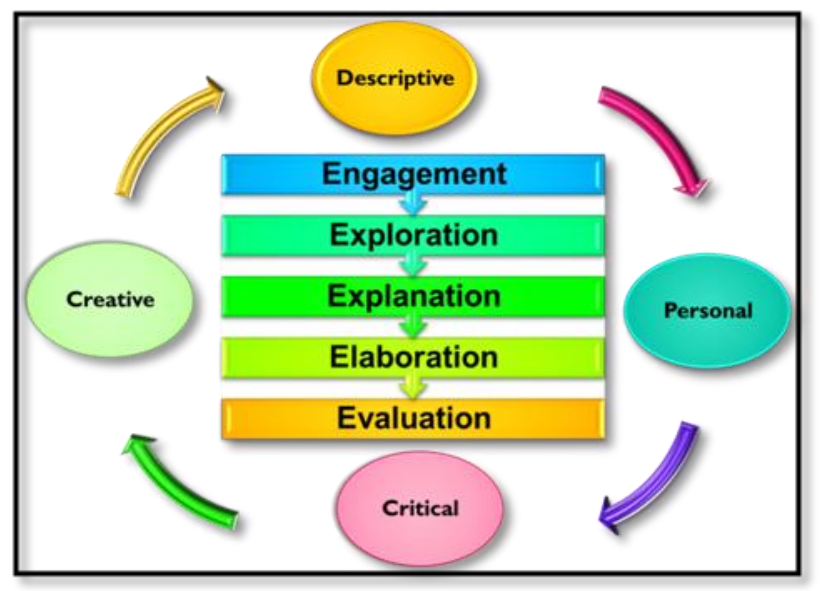

Figure 1:Creative Circle reading instructional model

Moreover, this model promotes effective reading and creative thinking by encouraging students to go beyond finding out what is written on a page. According to the model, reading is viewed as a dialogue between reader and text in which the reader contributes as much as the text. Hence, reading becomes more than just a source of information and entertainment; it becomes an empowerment effort. Indeed, effective reading creates opportunities for readers to understand self and others as well as provides them with a source of imagination and inspiration.

The Creative Circles model evolves through four phases, which do not happen independently, but simultaneously. In the descriptive phase, the reader attempts to understand the content of the text through dealing with questions and queries that ask what, when, where, who, and why, which can be answered by the text. In the personal phase, readers react to the text through expressing their own feelings and emotions drawing on their real life experiences in conditions related to the text. Through this process, the reader confirms, evaluates or expands his experience in relation to the information from the text. The questions that can be asked in this particular phase might be: How do I feel about this? What do I like/dislike? or How has my experience differed? In the critical phase, the reader engages in a critical reflection, which involves evaluating and passing judgments on the purpose, bias and truthfulness of the information in 
the text. The type of questions in this phase could be: Is this statement right?, What would be the consequences?, What are the author's intentions? or what is point the author tries to prove? Finally, in the creative phase, the reader is moved to action by the text and use their imagination and curiosity to create constructive ideas through elaborating and transforming the concepts and thoughts provided in the text. The type of questions to guide the dialogue in this phase might be: What do I know now that will empower me?, How can we improve life/conditions/relations? or In what ways can we act differently?

\section{RELATING CREATIVE CIRCLES TO THE CONSTRUCTIVIST THEORY}

As Keser (2003) points out, many of the existing models in the area of education as well as teaching process are rooted in a constructivist learning theory. Constructivism theorizes that learners construct knowledge and meaning from their experiences reflecting on those experiences (Kilavuz, 2005). The generative model of Creative Circles approach is closely related to the constructivist teachings. It encourages students' active participation, collaboration, reflectivity and inquiry-based learning. Each of the phases in Creative Circles is having a particular function, both serving a consistent and effective teaching as well as in improving learners' perceptions, knowledge, attitudes, and skills (Bybee, Taylor, Gardner, Scotter, Powell, Westbrook, \& Landes, 2006). When learners are inspired by forming a kind of mental disequilibrium or become interested to address a known or unknown real-life situation, the first phase in learning which is called Engagement occurs. The motivation and curiosity produced in the first phase guides the learners to the second step, called Exploration, through which they employ immediate and tangible experience to inspect, examine and collect information, as well as to check their predictions, and verify their hypotheses. Such data gives them the powers to set in motion and find some answers to the questions set off in the engagement phase. The exploration phase requires teachers to be supportive enough and assist learners to feel secure. They also need to provide a supervised and open question and answer so that learners can expose their misgivings regarding a particular point of discussion. The phase of Explanation follows as the third step in which the teacher becomes active in the sense that he unifies and makes sense of the observations and information from learners to generate valid justifications for their outcomes. He brings in suitable terms and notions relevant to the experience of learners at this moment of the development. Elaboration, as the fourth phase, follows with a new set of challenges presented to the learners aiming to let them apply their newly gained knowledge to suggest explanations, make decisions and see themselves enabled enough to analyse and come to logical conclusions. This phase is sometimes performed during another inquiry task or as an annex to the Exploration step. Finally, the Evaluation phase tries to establish whether or not learners have gained accurate understanding of the notions and ideas discussed and to see if they can take a broader view in generalising and transferring their skills to other contexts (Wilder \& Shuttleworth, 2004). With the help of the aforementioned phases, the Creative Circles approach can be applicable for learning new topics as well as making an effort to gain a deeper understanding of already familiar ones as learners can employ both their previous knowledge and experience and the newly encountered knowledge (Newby, 2004).

\section{SIGNIFICANCE OF CREATIVE CIRCLES IN EFL CONTEXTS}

Creative Circles approach can be a pedagogically vibrant platform for developing language acquisition in foreign language classrooms. This format of reading instruction provides opportunities for learners to model and judge the effectiveness of reading comprehension strategies. When learners read collaboratively in small groups, they can read texts more efficiently and incorporate reading skills to better understand the reading material. The cooperation between learners' strategic reading and active engagement with what they read can lead to motivated readers. In fact, social interaction and interactive learning that is associated with collaborative reading can sustain learners' motivation, which is necessary for successful reading effort (Mathewson, 1994).

This approach shares important aspects with influential teaching methods such as Communicative Approach (CLT) and Task Based Learning and Teaching (TBL). Creative Circles shares with CLT the common goal of developing learners' linguistic fluency. This occurs when learners read with their peers and collaborate to negotiate meaning, correct their understanding and use communication strategies (Shelton-Strong, 2012). In addition, Creative Circles seem to adhere to the requirements of TBL, which emphasizes exposure to rich comprehensible input, negotiation of meaning and motivation to listen, read and to speak the language (Willis, 1996). Creative Circles facilitate these conditions through reading and interacting within group discussions, which provide sufficient comprehensible input. Also, learners' motivation is increased through genuine communication efforts that provide them with ample time, space and freedom to deal with clearly defined reading tasks. This is coupled with the benefits of peer- and teacher-led feedback, which are crucial for language acquisition (Larsen-Freeman \& DeCarrico, 2010).

Moreover, Creative Circles approach may have several positive effects on EFL learners (See Figure 2). First, this approach can enhance learners' attitudes and self-confidence through working independently and collaboratively in preparation for and participation within group discussions about what is being read. Second, it can provide readers with incidental learning opportunities, which can raise their awareness, improve their achievement and encourage reflectivity in meaningful reading activities. Third, this type of approach advocates reading for pleasure, reading habits and noticing incidents that allow for L2 acquisition to take place (Spada \& Lightbown 2010). Fourth, since the approach is collaborative in nature and easy to implement, it can be useful in mixed-abilities classes as well as with other school subjects (AlSufyani, 2010). Fifth, readers' creative thinking can be enhanced through creativity activities in the pre and post reading phases, which can help to round up, consolidate, and extend their understanding and interpretation of the 
text being read. In fact, students are given the chance to creatively elaborate on the topic independently and collaboratively, which allows for further language use and fluency.

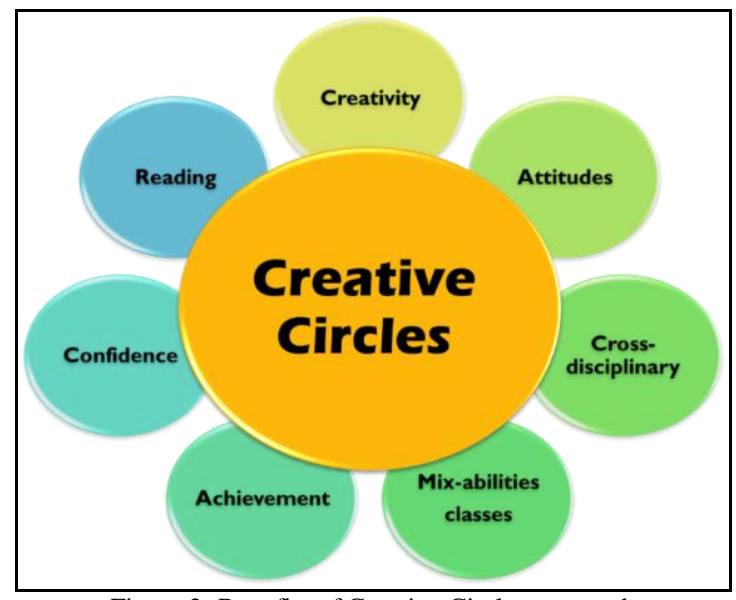

Figure 2: Benefits of Creative Circles approach

Sixth, another important aspect to Creative Circles is its encouragement of peer evaluation through constant involvement in discussions and comments about each member's contribution and effort. It also encourages selfevaluation using a reflective journal in which learners respond to questions about their progress and feelings, performance and improvement plans. Seventh, as the teacher's role moves away from lecturing towards facilitating and monitoring, he has enough opportunities to evaluate language use and overall performance to further improve language learning/teaching experiences.

\section{METHODOLOGY}

\section{Context of the Study}

The experiment was conducted at Saudi public intermediate school in Jeddah City. This school, which is situated close to the city centre, consisted of three levels (three classes per level), and the average number of students per class is between 25 and 30. One of the reasons for choosing this particular school was that it is located in a major city. This is an important issue as the general tendency for most Saudi families is to move from rural to urban areas where the infrastructure is well developed and major facilities, schools, universities and job opportunities are available. Another reason was that it is quite typical of most public middle school in Jeddah City and in most Saudi cities with regard to its facilities, teaching materials, resources and number of staff and students. Also, the EFL teacher at this particular school expressed his interest in the experiment and volunteered to participate, which was a positive indication for a good starting point in achieving the goals of the study.

The 90 student participants (age 15 to 16) were all male (as schools in Saudi Arabia adopt single-sex policy in education), and they have similar cultural and economic background. In order to create homogenous classes, all efforts were made by the school to evenly distribute students of different achievement levels among classes of the same stage.

The textbook 'Say it in English' was designed by a group of Saudi EFL teachers and supervisors. The textbook consists of eight units (two of which are revision units); each unit is divided into four forty-five-minute lessons per week. It constitutes a hybrid syllabus combining structural, functional and topical threads which focuses on language functions in which grammar is carefully controlled and the skills of listening, speaking, reading and writing are developed gradually (Al-Yousef, 2007).

\section{Data Collection Tools}

A multi-strategy research was conducted in this study whereby different data collection methods were used to gather the necessary data. The tools included a proficiency test, a reading comprehension test and semi-structured interviews. Also, the teacher and students in the experimental group were asked to keep reflective journals during the experiment. What follows is a detailed description of each tool.

\section{Language Proficiency Test}

At the beginning of the first term in 2014, the TOEFL Junior Standard Test was administered to the three participating classes to identify the Common European Framework of Reference for Languages (CEFR) level of the students in general. This was done to make sure that the three groups were homogenous, and that no significant differences existed between them with regard to their language proficiency prior to the planned intervention. The scores were also mapped to CEFR levels to help in understanding students' English proficiency levels. The TOEFL Junior Standard Test is intended for students ages 11+ and can be used for placement in language classrooms. The twohour test consists of 126 items testing three areas: listening comprehension (42 items), reading comprehension (42 items), and language form and meaning (42 items). Results of the test showed that the students' proficiency level was 
between levels A1 and A2 in the CEFR system. The scores also did not show any significant differences between the three groups.

Reading Comprehension Test

The TELC (The European Language Certificates) reading comprehension test was adopted and administered in order to answer the second question of the present study which was about whether Creative Circles approach could improve students' reading comprehension. Two forms of reading comprehension section of TELC were used as pre and post tests before and after the intervention. The TELC test, which is recognized by Association of Language Testers in Europe (ALTE), was used because it has an international recognition at universities, companies and government authorities as well as a transparent world-renowned CEFR level system. It offers authentic and practical examination tasks that are especially designed for A1-A2 level of foreign language learners (TELC, 2014). The reading comprehension test was used to examine whether Creative Circles as an instructional approach had any effect on students' reading comprehension ability.

Each test form had a total of 12 matching items based on three reading passages. The answers were scored as either correct or incorrect and the highest achievable score was 24 . The test forms were sent to a number of lecturers and $\mathrm{PhD}$ students to validate the tests' clarity, suitability for the measured skills, appropriacy for students' level and timing. Then, the two forms were piloted with participants who were not part of the actual experiment. The aims were to measure the tests' reliability, detect possible flaws in testing procedures and identify unclear or ambiguous items. The internal consistency reliability coefficients (Cronbach's alpha) for Forms A and B based on students' performance in the pre-test were found to be 0.80 , and 0.83 , respectively.

Semi-structured Interviews

After the intervention, a series of interviews were carried out with thirteen $3^{\text {rd }}$ grade middle school EFL learners from the experimental group as well as with their teacher. The researcher attempted to obtain information about the attitudes of the participants towards the intervention programme as a whole. The interview process also utilized stimulated recall as an introspect method. This was a way, as recommended by Gass and Mackey (2000), of exploring the thoughts and reflections of participants while they were doing activities from the intervention programme aided by extracts of the taught lessons.

The duration of each interview sessions ranged approximately between 30 to 45 minutes, and they were administered in the participants' first language to overcome concerns of foreign language proficiency or miscommunication. The questions considered general and easy to answer were asked at the beginning of the interview in order to engage respondents and put them at ease. Each interview was digitally audio-recorded to help gather as much relevant data as possible and remain attentive to the interviewed during the sessions.

\section{Teacher and student reflective journals}

During the intervention, the teacher and students kept reflective journals which were filled in after each lesson. These journals were based on de Bono's Six-Thinking-Hats model which is a system of conscious thinking about an issue in a certain direction for a certain amount of time (de Bono, 1999). Using this model enabled the researcher to capture the teacher's experience, feelings, reactions, attitudes, views, ideas and suggestions about the intervention programme. The generated data could be related to other data collection methods in this research such as interviews in order to achieve triangulation. Thus, after every lesson, participants were given the chance to express their opinions and thoughts about the lesson: what they achieved, what went well during their reading, what went wrong, how they felt about the reading tasks and what they could do to improve their performance.

\section{Data Collection Procedures}

The data collection process consisted of three stages. During the first stage, three third grade intermediate classes from the school which facilitated the experiment were assigned, one as the experimental group and the other two as the comparison groups. The three classes took the proficiency test and the first form of the reading comprehension test. The researcher made his best efforts to make the items and the instructions of the tests clear and within a reasonable time frame; and that students were allowed to ask for clarification at any time during the tests. Participants were assured that the results would not have any negative consequences on their academic achievement. The collected data in this stage were analysed later in order to compare and integrate it with the data gathered from the other stages of the study.

The second stage involved the application of the intervention which employed the Creative Circles approach. The teacher, who had been previously trained to use this teaching approach, taught all three classes. Students in the experimental group were taught reading comprehension lessons via Creative Circles approach for approximately eleven weeks. The first comparison group were introduced to some of the lessons that were taken by the experimental group. As for the second comparison group, students did not do any of the tweaked lessons. In this way, the researcher was able to compare between all three groups and decide whether Creative Circles improved students' reading comprehension. Furthermore, after each lesson, the teacher of the experimental group and his students completed their reflective journals.

In the third stage, towards the end of the experiment, the study tools: the second form of the reading comprehension test was administered again to all the participating classes. Moreover, thirteen students from the experimental group and their teacher were interviewed in order to share their accounts and views about Creative Circles approach and how it influenced teaching/learning reading comprehension. 


\section{RESULTS}

As discussed earlier, the TELC (The European Language Certificates) reading comprehension test was adopted and administered in order to address the question of whether Creative Circles could improve students' reading comprehension. Two forms of reading comprehension test were administered (as pre- and post-tests) before and after the implementation of Creative Circles on the experimental group, the other two groups also took the reading comprehension tests (pre and post) for comparison reasons. The obtained results, which will be discussed next, showed that the experimental group made a significant improvement in their reading comprehension in the post phase of reading comprehension test compared to the comparison groups, indicating the positive effect of Creative Circles on students' reading comprehension.

In this section, the results of the pre- and post-tests will be presented and the necessary comparisons will be made to identify the impact of Creative Circles on students' reading comprehension. Moreover, relevant findings from qualitative tools (interviews and journals) will be provided accordingly.

\section{Pre Intervention Phase}

Before the start of the intervention programme, the first form of the reading comprehension test was administered to the three participating groups. A one-way between-groups analysis of variance (ANOVA) test was carried out to examine whether any significant differences exist in the mean scores among the three groups. Table 1 below shows the mean scores and standard deviation for each group in the pre-test, whereas Table 2 shows the results obtained from the ANOVA test of students' scores.

TABLE 1:

DESCRIPTIVE STATISTICS RESULTS FOR PRE INTERVENTION PHASE READING TEST

\begin{tabular}{l|l|l|l|l|l|l|l}
\hline & $N$ & Mean & Std. Deviation & \multicolumn{2}{l}{ Confidence Interval for Mean } & Min & Max \\
\cline { 5 - 7 } & & & & Lower Bound & Upper Bound & \\
\hline Comparison group1 & 30 & 11.67 & 2.24 & 10.8 & 12.5 & 6 & 16 \\
Comparison group 2 & 30 & 10.70 & 3.63 & 9.3 & 12.0 & 5 & 18 \\
Experimental Group & 30 & 11.70 & 3.06 & 10.5 & 12.8 & 6 & 18 \\
\hline
\end{tabular}

An alpha level of .05 was used for all analyses. The test for homogeneity of variance was not significant [BrownForsythe $F(2,76)=1.05, p>.05$ ] indicating that this assumption underlying the application of ANOVA was met. The ANOVA of the pre intervention phase reading comprehension test (See Table 2) did not reveal any statistical significant differences between the three groups: $[F(2,87)=1.05, p>.05]$, indicating that all three groups had similar levels of reading comprehension abilities prior to implementing Creative Circles.

TABLE 2:

ANOVA AMONG THE GROUPS IN THE PRE INTERVENTION PHASE READING TEST

\begin{tabular}{l|lllll}
\multicolumn{5}{c}{ ANOVA AMONG THE GROUPS IN THE PRE INTERVENTION PHASE READING TEST } \\
\hline & Sum of Squares & $d f$ & Mean Square & $F$ & Sig. \\
\hline Between Groups & 19.3 & 2 & 9.678 & 1.05 & .35 \\
Within Groups & 801.2 & 87 & 9.210 & & \\
Total & 820.6 & 89 & & & \\
\hline
\end{tabular}

\section{Post Intervention Phase}

After implementing the Creative Circles to the experimental group, another equivalent form of the reading comprehension test was administered to the three participating groups. An ANOVA test was conducted to examine whether any significant differences exist in the mean scores among the three groups. Table 3 shows the mean scores and standard deviation for each group in the post-test, whereas Table 4 shows the results obtained from the ANOVA test of students' scores.

TABLE 3:

DESCRIPTIVE STATISTICS RESULTS FOR POST INTERVENTION PHASE READING TEST

\begin{tabular}{|c|c|c|c|c|c|c|c|}
\hline & \multirow[t]{2}{*}{$N$} & \multirow[t]{2}{*}{ Mean } & \multirow[t]{2}{*}{ Std. Deviation } & \multicolumn{2}{|c|}{ Confidence Interval for Mean } & \multirow[t]{2}{*}{ Min } & \multirow[t]{2}{*}{$\operatorname{Max}$} \\
\hline & & & & Lower Bound & Upper Bound & & \\
\hline Comparison groupl & 30 & 12.6 & 2.1 & 11.85 & 13.42 & 8 & 17 \\
\hline Comparison group 2 & 30 & 11.9 & 3.1 & 10.80 & 13.13 & 7 & 19 \\
\hline Experimental Group & 30 & 15.8 & 2.7 & 14.84 & 16.89 & 10 & 22 \\
\hline
\end{tabular}

An alpha level of .05 was used for all analyses. The test for homogeneity of variance was not significant [Levene $F$ ( 2 , $87)=2.32, p>.05$ ] indicating that this assumption underlying the application of ANOVA was met. The ANOVA of the post intervention phase reading comprehension test (See Table 4) revealed significant statistical differences between the three groups: $[F(2,87)=18.045, p<.05]$, indicating that the participating groups had different levels of reading comprehension after the implementation of Creative Circles to the experimental group. To find out exactly where the differences among the groups occur, a post-hoc test was needed. 
TABLE 4:

ANOVA AMONG THE GROUPS IN THE POST INTERVENTION PHASE READING TEST

\begin{tabular}{l|lllll}
\hline & Sum of Squares & $d f$ & Mean Square & F & Sig. \\
\hline Between Groups & 261.089 & 2 & 130.544 & 18.045 & .000 \\
Within Groups & 629.400 & 87 & 7.234 & & \\
Total & 890.489 & 89 & & & \\
\hline
\end{tabular}

The post-hoc comparisons using the Tukey HSD test (Table 5) indicated that the mean score for the experimental group $(M=15.8, S D=2.7)$ was significantly different from both comparison groups, Comparison Group1 $(M=12.6$, $S D=2.1)$ and Comparison Group2 $(M=11.9, S D=3.1)$. The results also show that Comparison Group1 did not differ significantly from Comparison Group2. The actual difference in mean scores between the groups was considerably high as the calculated effect size using eta squared was 0.64 .

TABLE 5:

MULTIPLE COMPARISONS TUKEY HSD TEST BETWEEN GROUPS FOR POST READING TEST SCORES

\begin{tabular}{|c|c|c|c|c|c|c|}
\hline \multirow[b]{2}{*}{ (I) Group } & \multirow[b]{2}{*}{ (J) Group } & \multirow[b]{2}{*}{ Mean Difference } & \multirow[b]{2}{*}{ Std. Error } & \multirow[b]{2}{*}{ Sig. } & \multicolumn{2}{|c|}{ Confidence Interval } \\
\hline & & & & & $\begin{array}{l}\text { Lower } \\
\text { Bound }\end{array}$ & $\begin{array}{l}\text { Upper } \\
\text { Bound }\end{array}$ \\
\hline \multirow{2}{*}{ Comparison groupl } & Comparison group 2 & .667 & .694 & .604 & -.99 & 2.32 \\
\hline & Experimental Group & $-3.233^{*}$ & .694 & $.000 *$ & -4.89 & -1.58 \\
\hline Comparison group 2 & $\begin{array}{l}\text { Comparison group1 } \\
\text { Experimental Group }\end{array}$ & $\begin{array}{l}-.667 \\
-3.900^{*}\end{array}$ & $\begin{array}{l}.694 \\
.694\end{array}$ & $\begin{array}{l}.604 \\
.000 *\end{array}$ & $\begin{array}{l}-2.32 \\
-5.56\end{array}$ & \begin{tabular}{|l|}
99 \\
-2.24
\end{tabular} \\
\hline \multirow{2}{*}{ Experimental Group } & Comparison group1 & $3.233^{*}$ & .694 & $.000 *$ & 1.58 & 4.89 \\
\hline & Comparison group 2 & $3.900^{*}$ & .694 & $.000^{*}$ & 2.24 & 5.56 \\
\hline
\end{tabular}

*. The mean difference is significant at the 0.05 level.

From the findings presented above, it can be concluded that students who were involved in the Creative Circles intervention exhibited better reading comprehension skills as they outperformed their peers in the other comparison groups. Moreover, the large effect size that was calculated indicates that 64 percent of the variance in students' reading comprehension performance could be explained by the implementation of Creative Circles approach.

In addition, the journals and interviews with students from the experimental group and their teacher provided additional insights into the impact of Creative Circles on students' reading comprehension. These are discussed next.

Students'views

Interview and journal data that were gathered from students in the experimental group after the implementation of Creative Circles approach provided some insights into students' use of careful and expeditious reading skills. Expeditious reading emphasizes the macrostructure understanding of texts and selectivity in reading, whereas careful reading aims at detailed comprehension and close reading of texts. What follows is an exploration and an interpretation of students' views and perceptions of their reading skills in relation to these two types of reading.

With regard to expeditious reading skills, students seem to be generally satisfied with what they had achieved in reading skills such as skimming and scanning. For example, Ali indicated that the activities that he was involved in enabled him to "get the overall impression of a passage through learning about text types and identifying text topic". When asked about the significance of such improvement, he explained that it allowed students to recognize the main purpose of what they read as well as some features that were related to certain types of genres. Omar added that:

"being taught explicitly about different purposes of texts has helped me find out whether a passage was written to inform, instruct, or entertain".

Moreover, students commented, in their own words, on scanning, which is another reading skills related to expeditious type of reading. Some students such as Jalal and Ahmad mentioned that it was 'exciting' for them to find specific details (e.g. names, figures, dates) and that even though they were used to scanning exercises, they believed Creative Circles addressed the 'need to do scanning activities' more than what they were doing in the past. It seems that this type of activity improves students' attitudes and boosts their confidence, as it does not require a lot of syntactic processing or macrostructure building up. Furthermore, the majority of the interviewees mentioned that prior to the intervention there was not enough emphasis on skills such as 'activating prior knowledge', 'previewing' and 'making predictions'. All of the attention, in their opinion, was paid to reading aloud and answering questions based on the reading passage.

As for careful reading skills, the majority of students pointed out that they had never been involved in activities that were geared towards developing careful reading skills before Creative Circles intervention. When asked about the activities they found new to them, many students mentioned activities like using 'grammatical function, word root and contextual clues to guess the meaning of new words', 'establishing a plain sense of a text through interpreting discourse markers', 'recognizing the functional value of a sentence', 'recognizing text structure', 'making inferences' and 'evaluating a text'. As these skills were included in the Creative Circles intervention, most students expressed positive comments about the benefits of being involved in such an experience. For example, Nasser said:

"I have found learning about these skills very useful. I like the design of these activities. It is gradual and really makes me think deeper so that I could read better. I believe reading is better learned this way".

Ahmad also maintained that: 
"To me, this [the intervention] was very useful. I have never seen such organization, design and clarity. There were so many exciting reading skills activities. I also noticed my friends enjoying the lessons. Most students were active".

Omar compared Creative Circles lessons to reading lessons in his textbook and said: "The way the lessons were designed here [the intervention] is far better than the organization of the textbook, it really gives more attention to reading". However, few students such as Jalal and Ali expressed their wish to be allowed more time and practice with reading skills. They also criticized Creative Circles for having 'too many activities'. Nonetheless, they maintained that the programme was 'really beneficial and exciting'

Teacher's views

The teacher of the experimental group offered some important and interesting observations in his interview after the implementation of Creative Circles approach. Ayman, the participating teacher, held very positive view of Creative Circles' role in introducing and developing students' reading skills in English. He described Creative Circles as " $A$ very successful programme". He valued this programme's significance in engaging and improving students' reading skills. For example, he noted:

"I found significant improvements thanks to creative circles. Many students liked the way in which the lessons are presented, they enjoyed the activities and they showed more interest than they used to. They were more engaged and on task, they also showed huge progress in their reading abilities".

He offered a range of reasons why he thought Creative Circles approach had a positive effect on students' reading skills. As demonstrated by the earlier quote, 'improving students' attitudes' is one of the reasons. Another reason was the 'logical structure and organization of Creative Circles'. He commented "I really liked the way the programme was organized. It was very clear and meaningful to me and my students". Moreover, he described the "reading skills training-oriented' aspect of the intervention as being an important factor in improving students' reading skills. Aymen pointed out "It [Creative Circles approach] is desperately needed. Students lack many reading skills and had no previous training before". According to Ayman, 'Raising students' awareness' of reading skills was considered a crucial reason for the success as well a significant outcome of this programme. He maintained:

"Students have become conscious of reading skills, what and how these skills help in comprehension. They had the chance to try them over and over again. Our discussions as well as the journals they kept helped them internalize and appreciate these skills more, something they had never experienced before".

This quote also signifies the importance of having a 'reflective attitude'. The journals students kept gave them the opportunity to clarify their ideas, gain insights and deepen their understanding of reading skills in a way that encourages them to monitor their own comprehension and to be empowered and independent.

\section{DISCUSSION}

The analysis of posttest reading comprehension test indicated that the experimental group was significantly different from both comparison groups. Based on this finding, it could be concluded that students who were taught via Creative Circles approach exhibited better reading comprehension skills as they outperformed their peers in the other comparison groups with a large effect size. To understand this result, one must discuss the outcomes of this approach in order to relate them to the observed positive change in students' reading comprehension.

A key outcome of Creative Circles approach from the reactions of learners in the experimental group and their teacher was the increase in students' reading comprehension and use of expeditious and careful reading skills compared to traditional teaching methods, as observed by both the teacher and the students. This result is in agreement with the findings of various studies on the positive effect of collaborative reading on reading comprehension (e.g., Ghaith, 2003; Stevens, 2003; Takallou \& Veisi, 2013).

Collaborative reading as learning technique is considered an effective tool in improving students' ability to read with comprehension. When students read collaboratively, they jointly brainstorm, interact, decode texts, evaluate and make decisions together, something that requires students to reflect on their knowledge and share generalizations and elaborations with others. This exchange of ideas and experiences is an effective way to develop students' "depth of processing" (Stevens, Slavin \& Farnish, 1991) as students, in group work, discuss and communicate their thought processes and problem-solving strategies to one another. Moreover, collaborative reading involves questioning, discussion, and cooperative learning which makes it highly effective in improving students' use of comprehension strategies and retention (Caposey \& Heider, 2003).

In addition, this study reveals that both students in the experimental group and their teacher appreciated explicit teaching of reading skills and the clarity, organization and gradual progression of the activities. This finding is consistent with other studies (e.g., Pressley, 2006; McNamara, 2007) which maintain that explicit teaching of reading skills helps students become expert readers and develops a more positive attitude towards reading. The explicit teaching of reading skills involves explaining what reading comprehension skills are, and where, when, how, and why they can be used/adapted to various situations. It also includes modelling reading skills, and providing feedback to students (Pressley, 2006). This helps students develop an awareness of the interactive nature of reading process and the effective role of comprehension-fostering activities. Although, some researchers (e.g., Alsamadani, 2009) claim that explicit teaching of reading skills does not improve comprehension, the mounting evidence, including findings of this study, is 
in support of effectiveness of explicit instruction of reading skills in improving L1/L2 reading comprehension (Akkakoson \& Setobol, 2009; Kazemi, Hosseini \& Kohandani, 2013).

One of the important advantages of Creative Circles approach is its attention to both low-level and high level reading processes. Based on the data obtained from the experimental group's reading questionnaire, journals and the interviews with both students and their teacher, both levels of reading comprehension were facilitated. Both levels of processing are considered the building blocks of comprehension (Grabe, 2009). Bearing in mind that Saudi EFL learners are poor readers, this approach provides students with sufficient practice of recommended low-level processes such as word recognition, knowledge of grammar and basic sentence structure. It also emphasizes high-level processes such as drawing on background knowledge, recognizing and processing discourse structure and markers, evaluating text information and monitoring one's comprehension. However, it is important to stress the fact that long-term practice and extensive exposure to target language texts is the only way to develop mastery of reading comprehension skills as L2 reading is a long and highly complicated process (Ibid.).

Another key outcome is the significant increase in students' awareness of their own thinking as well as the various reading skills used when a text is approached, which pertains to the concept of 'metacognition'. Through the explicit teaching and training of reading skills and the use of tools such as student journals and thinking activities, students were given enough opportunities to practice and internalize skills; hence, students obtained active control over their cognitive processes. Metacognition is very influential in reading comprehension (Aksan \& Kisac, 2009). It involves two interacting elements: knowledge of cognition and regulation of cognition (Kazemi, Hosseini \& Kohandani, 2013). Knowledge of cognition in reading comprehension consists of activities such as identifying reading skills, knowing how to deploy these skills and knowing when and why these skills are applied, whereas regulation of cognition involves all the mental processes that are used to control and monitor one's own reading (Ibid.). Based on the previous explanation, it is quite clear that metacognition is extremely important for the improvement of students' reading comprehension, and to pay more attention to metacognition is of paramount priority.

Furthermore, students in the experimental group as well as their teacher noted that Creative Circles has immensely helped students address the issue of vocabulary, which is considered a very influential factor in improving or hindering reading comprehension (Rouhi \& Negari, 2013). Both vocabulary knowledge and reading comprehension have a twodirectional relationship as vocabulary knowledge helps learners comprehend the text and the process of reading contributes to increasing learners' vocabulary size (Maher, 2008). The new approach and the accompanying materials provided students with sufficient training opportunities to explore and learn new vocabulary through word attack skills such as guessing the meaning of unfamiliar words through identifying grammatical functions, examining prefixes, suffixes and word roots, using synonyms, antonyms and contextual clues, interpreting pro-forms, discourse markers and functional value of words. Teaching these skills as well as text-attack skills was a rarity in the Saudi EFL context as described by students, teachers and supervisors in this study and in the findings of other studies (e.g., Sofi, 2015). Therefore, providing students with the knowledge and practice of these important vocabulary-learning skills is highly recommended.

Moreover, the results of this study showed that Creative Circles approach is an efficient and flexible tool to use to facilitate the development of reading comprehension skills in large and mix-abilities classes. Students from the experimental group believed that the approach has improved their reading comprehension. They also indicated that it was very useful and worked well with their level of language proficiency as well as their crowded class. The teacher echoed these points and added the observation that poor readers were actively involved during the lesson. These findings were supported by that of Khan (2011), Goodmacher and Kajiura (2010) and Takallou and Veisi (2013) who maintain that collaborative reading can assist teachers in large and mixed-abilities classes who cannot attend to all students needs and queries during the lesson. Groups help address the issues of discovering and attending to all of the reading problems in a more effective learning environment which promotes interaction, communication, socio-linguistic competence (Bolukbas, Keskin, \& Polat, 2011; Ning, 2011). In addition, in this kind of environment, students are able to learn from each other in a non-threatening environment that provides planned as well as incidental learning opportunities.

\section{IMPLICATIONS AND RECOMMENDATIONS}

Based on the earlier discussion about the positive effect of Creative Circles approach on EFL learners' reading comprehension, a number of recommendations can be suggested. First, given the unsatisfactory English language proficiency level of Saudi students at different academic stages, it is quite important to introduce English to Saudi students at an earlier stage in their life. Even though English language is introduced to Saudi students at grade 4 in elementary stage, it does not seem to have a significant impact on the development of their language abilities as students learn English during two periods of 35 to 45 minutes per week. Therefore, the idea of exposing students to English at the first grade and allocating more classes to language learning is worth considering as recent studies suggest that most youngsters can successfully learn more than one language from their earliest years (Kuhl, 2004).

Second, based on the positive effect of collaborative reading in this study, it is recommended that this mode of teaching be adopted at different school levels. The findings of this study have shown that collaborative reading develops students' reading comprehension and that it is very useful in large and mixed-abilities classes, which is the case in 
Saudi schools. Furthermore, Creative Circles has helped address the issue of dealing with unfamiliar vocabulary items in reading passages, which is considered the most problematic aspect as reported by EFL students and teachers as well.

Third, the findings of this study highlight the important role of metacognition in developing students' reading comprehension, which is also the conclusion of several studies (e.g., Razi \& Çubukçu, 2014). Therefore, metacognitive strategies (declarative, procedural, and conditional) should be fostered in Saudi EFL reading classes through familiarizing students with these strategies, modelling them to students and providing enough opportunities for students to practice them. This study proposes reflective journals and explicit reading skills instruction as methods of fostering students' metacognitive awareness, which could eventually facilitate the comprehension processes.

The fourth recommendation of this study is for all those concerned (Saudi educational policy makers, textbook designers, EFL supervisors and teachers) to encourage consistent explicit teaching of reading skills to Saudi EFL readers. Learners should be aware of reading skills and have sufficient practice and training on how to use low-level and high-level reading processes. In fact, most recent research findings concur on one fact that explicit reading skills instruction and training significantly improve students' comprehension in both L1 and L2 (e.g., Cubucku 2008; Grabe, 2009).

Closely related to the previous suggestion, it is highly recommended that explicit reading skills instruction is emphasized not only in L2 but also in L1 as well. This is based on the critical role that L1 plays in L2 reading development as proposed by different well-known theories on L1 reading skills transfer effects on L2 reading development such as the Interdependence Hypothesis, The Common Underlying Proficiency Theory and the Threshold Hypothesis. It is important to identify ways in which L1 can support EFL learners' reading development. This could probably involve building students' metacognitive, metalinguistic and sociocultural awareness as well as cognates and morphological similarities (Grabe, 2009).

In closing, implementing extensive reading programmes in Saudi EFL context is recommended. Research evidence shows that the average time students spend on reading is very small (between seven and 15 minutes per day). Therefore, students need to be engaged in extensive reading at school and at home as related literature supports the effectiveness of extensive reading on student's reading comprehension, motivation and attitudes, vocabulary growth, conceptualknowledge growth and reasoning (Ibid.). Some of the most popular extensive reading programmes include Sustained Silent Reading (SSR), Free-reading Time, Reading Lab, class library corner and school library (National Reading Panel, 2000). Regardless of names and labels, the most important goal for extensive reading programmes is to have students read materials that they want to read even on their own.

\section{REFERENCES}

[1] Aksan, N., \& Kisac, B. (2009). ‘A descriptive study: Reading comprehension and cognitive awareness skills'. Procedia-Social and Behavioral Sciences'. 1(1), pp.834-837. doi: 10.1016/j.sbspro.2009.01.149.

[2] Alfassi, M. (2004). 'Reading to learn: Effects of combined strategy instruction on high school students'. Journal of Educational Research. 97(4), pp.171-184.

[3] Al-Mansour, N. S., \& Al-Shorman, R. E. A. (2011). 'The effect of teacher's storytelling aloud on the reading comprehension of Saudi elementary stage students.' Journal of King Saud University -Languages and Translation, 23(2), pp.69-76.

[4] AL-Nifayee, A. M. (2010). The Effectiveness of the Instrumental Enrichment Approach on The Enhancement of Reading Comprehension Skills of Preparatory Stage Pupils with English Language Learning Difficulties. (Master's thesis), Taif University, Saudi Arabia.

[5] Al-Nujaidi, A. (2003). The relationship between vocabulary size, reading strategies, and reading comprehension of EFL learners in Saudi Arabia, Unpublished Doctoral Dissertation, Oklahoma State University.

[6] Alsamadani, H. (2009). The Relationship between Saudi EFL College-Level Students' Use of Reading Strategies and Their EFL Reading Comprehension, Unpublished Doctoral Dissertation, Ohio University.

[7] AlSufyani, N. (2010). The Effect of Using Learning Cycle in Teaching Physics on Developing Junior Secondary Students' Achievement and on Their Creative Thinking skills. M.A., Umm Al Qura University, Saudi Arabia. Retrieved August 4, 2015 , from http://uqu.edu.sa/lib/digital_library (12116).

[8] Al-yousef, H. (2007). An evaluation of the Third Grade intermediate English coursebook 'Say it in English'. Unpublished MA thesis, Riyath University, Saudi Arabia.

[9] Atkin, J.M., \& Karplus, R. (1962). 'Discovery or invention?’ The Science Teacher. 29(5), pp.45-51.

[10] Bolukbas, F., Keskin, F., \& Polat, M. (2011). 'The effectiveness of cooperative learning on the reading comprehension skills in Turkish as a foreign language.' The Turkish Online Journal of Educational Technology, 10(4), pp.330-335.

[11] Bybee, R. W., Taylor, J.A., Gardner A., Scotter, P. V., Powell, J.C., Westbrook, A. \& Landes, N. (2006). The BSCS 5E instructional model: origins and effectiveness. Office of Science Education National Institutes of Health, pp.1-80.

[12] Caposey, T., \& Heider, B. (2003). Improving reading comprehension though cooperative learning (CS 512 283). Illinois, United States: Saint Xavier University and Skylight Professional Development Field-Based Master's Program.

[13] Collins, D., \& Collins, A. (2002). Advancing reading achievement: becoming effective teachers of reading through collective study. [Greensboro, NC?]: Regional Educational Laboratory at SERVE.

[14] de Bono, E. (1999). Six thinking hats. New York: Little, Brown and Company.

[15] Educational Testing Services. (2009, 2010, 2011, 2012). Test and Score Data Summary for TOEFL Internet-Based and PaperBased Tests, Retrieved November 11, 2012 from: http://www.ets.org.

[16] Gass, S. M., \& Mackey, A. (2000). Stimulated recall methodology in second language research. Mahwah, NJ: Lawrence Erlbaum Associates. 
[17] Ghaith, G. M. (2003). Effects of learning together model of cooperative learning on English as a foreign language reading achievement, academic self-esteem, and feelings of school alienation. Bilingual Research Journal, 27(3), pp. 451-474.

[18] Goodmacher,G. \& Kajiura, A. (2010). Collaborative and communicative reading. Polyglossia, 18, pp. 25-30.

[19] Gough, P., Hoover, W., \& Peterson, C. (1996). Some observations on a simple view of reading. In C. Cornoldi \& J. Oakhill (Eds.), Reading comprehension difficulties: Processes and interventions. Mahwah, NJ: Lawrence Erlbaum Associates.

[20] Grabe, W. (2009). Reading in a second language: Moving from theory to practice. New York: Cambridge University Press.

[21] Karplus, R., \& Thier, H. (1967). A New Look at Elementary School Science, New Trends in Curriculum and Instruction Series. Chicago, IL: Rand McNally.

[22] Kazemi, M., Hosseini, M. \& Kohandani, M. (2013). Strategic Reading Instruction in EFL Contexts. Theory and Practice in Language Studies, 3 (12), pp. 2333-2342.

[23] Keser, Ö.F. (2003). Designing and implementing a constructivist learning environment for physics education. PhD Thesis, Karadeniz Technical University, Trabzon.

[24] Khan, I. (2011). An Analysis of Learning Barriers: The Saudi Arabian Context. International Education Studies, 4(1), pp. 242247.

[25] Kilavuz, Y. (2005). The Effects of 5E Learning Cycle Model Based on Constructivist Theory on Tenth Grade Students' Understanding of Acid-Base Concepts. MA thesis. Middle East Technical University.

[26] Kuhl, P.K. (2004). Early language acquisition: cracking the speech code. Nature Reviews Neuroscience, 5(11), 831-843.

[27] Larsen-Freeman, Diana and Jeanette DeCarrico. (2010). 'Grammar' In Norbert Schmitt (ed.) An Introduction to Applied Linguistics. $2^{\text {nd }}$ edition. London: Hodder Education, pp.18-33.

[28] Maher, S. (2008). The relationship between vocabulary knowledge and reading comprehension of authentic Arabic texts. Brigham Young University.

[29] Mathewson, G. C. (1994). Model of attitude influence upon reading and learning to read. In R. B. Ruddell, M. P Ruddell, \& H. Singer (Eds.), Theoretical models and processes of reading (4th ed.). Newark, DE: International Reading Association.

[30] McNamara, D. S. (2007). Reading comprehension strategies: Theories, interventions and technologies. Mahwah, NJ: Lawrence Erlbaum Associates.

[31] National Reading Panel (2000). Teaching Children to read: An evidence based assessment of the scientific research literature on reading and its implications for reading instruction. (National Institute of Health Pub. No. 00-4769). Washington, DC: National Institute of Child Health and Human Development.

[32] Newby, D.E. (2004). Using inquiry to connect young learners to science. Retrieved April 13, 2014, from the website:http://www.nationalcharterschols.org/uploads/pdf/resource20040617125804using\%20Inguiry.pdf.

[33] Ning, H. (2011). Adapting cooperative learning in tertiary ELT. ELT Journal, 65(1), 60-70. Retrieved January 22, 2016, from http://dx.doi.org/10.1093\%2Felt\%2Fccq021.

[34] Nuttall, C. (1996). Teaching Reading Skills in a foreign language. Oxford: Heinemann.

[35] Pressley, M. (2006). Reading instruction that works: The case for balanced teaching (3rd ed.). New York: Guilford Press.

[36] Razi, S. \& Çubukçu, F. (2014). Metacognition and reading: Investigating intervention and comprehension of EFL freshmen in Turkey. Procedia - Social and Behavioral Sciences, 158, pp.288 - 295.

[37] Rouhi, M. \& Negari, G. (2013). EFL Learners' Vocabulary Knowledge and its Role in their reading Comprehension Performance. Journal of Second and Multiple Language Acquisition - JSMULA, 1 (2), pp.39-48.

[38] Shelton-Strong, S. J. (2012). Literature circles in ELT. ELT Journal, 66(2), 214-223. doi:10.1093/elt/ccr049.

[39] Sofi, D. (2015). Teaching Reading Comprehension Skills to Saudi Female Students at the University Levels: A Handbook for Teachers. Master Dissertation. University of San Francisco. Available at: < http://repository.usfca.edu/capstone/133> [Accessed 10.09.2015].

[40] Spada, N. and P. Lightbown. (2010). ‘Second language acquisition'. In N. Schmitt (ed.). Harlow: Longman. Willis, J. 1996. A Framework for Task-based Learning. Harlow: Longman.

[41] Stevens, J. R. (2003). Student team reading and writing: A cooperative learning approach to middle school literacy instruction, Educational Research and Evaluation. 9(2), pp.137-160.

[42] Stevens, R., Slavin, R. E., \& Farnish, A. M. (1991). The effects of cooperative learning and direct instruction in reading comprehension strategies on main idea identification. Journal of Educational Psychology, 83(1), 8-16.

[43] Takallou,F. \& Veisi, S. (2013). Implementing Cooperative Learning in a Reading Class. Report and Opinion, 5(1), pp. 16-23.

[44] TELC, The European Language Certificates. (2014). Why TELC - language tests? [online] Available at: < https://www.telc.net/en/candidates/why-telc-language-tests.html> [Accessed 14 January 2015].

[45] Wilder, M., and Shuttleworth, P. (2004). Cell inquiry: a 5e learning cycle lesson. Science Activities, 41(4), ProQuest Education Journals, 41(1), pp. 25-31.

[46] Willis, J. (1996). A Framework for Task-based Learning. Harlow: Longman.

\footnotetext{
Abdulaziz Ali Al-Qahtani is an applied linguistics PhD student at the University of Newcastle, UK. Prior to joining the university, he has taught English at Saudi secondary schools for 9 years, and worked as a English language inspector in Taif Educational Directorate for 8 years. He published a number of articles which are addressed issues in foreign language teaching/ learning; EFL reading comprehension; EFL teacher education; teaching methods, and critical discourse analysis. Currently, he works as a teacher assistant in MA level modules such as Introduction to TESOL and Thinking Skills at Newcastle University.
}

Mei Lin is the Degree Programme Director of the MA in Applied Linguistics and TESOL (Teaching English to Speakers of Other Languages) at Newcastle University, UK. Prior to joining the TESOL team, she has taught English as a foreign language at a secondary school and universities in China for 10 years, and worked on national research projects on educational policies and 
thinking skills in England. She is the author of numerous articles that address issues in professional development of second language teachers (esp. mediation and classroom discourse); teaching speaking and vocabulary; critical reading and writing in L2, and thinking skills in general English classes; collaborative learning; learning strategies and learner autonomy; language maintenance; bilingual code-switching, and bilingual education. 